\title{
THE EFFECTS OF SLEEP AND LACK OF SLEEP ON THE CEREBRAL CIRCULATION AND METABOLISM OF NORMAL YOUNG MEN ${ }^{1}$
}

\author{
By RENWARD MANGOLD, LOUIS SOKOLOFF, EUGENE CONNER, JEROME \\ KLEINERMAN, PER-OLOF G. THERMAN, AND SEYMOUR S. KETY \\ (From the Department of Physiology and Pharmacology, Graduate School of Medicine, the \\ Department of Anesthesia, Hospital of the University of Pennsylvania, and the Har- \\ rison Department of Surgical Research, University of Pennsylvania, \\ Philadelphia, Penna.)
}

(Submitted for publication October 21, 1954 ; accepted March 21, 1955)

Numerous hypotheses have been elaborated in attempts to explain the puzzling phenomenon of sleep. Thus sleep has been attributed to arterial anoxemia, to cerebral ischemia or anoxia, or to a generalized narcosis on the basis of one or another metabolic alteration. Little information is available, however, on the subject of cerebral metabolism and function during natural sleep. This might be explained to a great extent by the difficulties inherent in any experimental investigation during so labile a state as physiological sleep. Moreover, reasonably quantitative techniques for measuring the blood flow and oxygen consumption of the brain in unanesthetized animals and in man have become available only recently. Early attempts (1) to obtain at least qualitative information on the cerebral blood flow in man during sleep by means of brain plethysmography through trephine holes have yielded contradictory results. Later attempts with better methods of recording (2) have suggested a decrease in cerebral blood flow on passage from the waking state to short or long periods of sleep. More recently, Gibbs, Gibbs, and Lennox have attempted to obtain a better understanding of the cerebral circulation during sleep by means of the thermoelectric flow recorder (3). They found no significant alteration in cerebral blood flow during short periods of sleep in four epileptic patients. Unfortunately, arterio-cerebral venous oxygen differences were not measured simultaneously, and no information on the important question of the oxygen consumption of the brain was obtained.

Recently developed methods permit a more quantitative determination of the cerebral blood

1 This investigation was supported in part by a research grant from the Division of Research Grants and Fellowships of the National Institutes of Health, United States Public Health Service. flow and oxygen consumption during natural sleep. It was to obtain such information as well as to test some of the previously proposed hypotheses that the present study was undertaken.

\section{METHOD}

Attempts to measure cerebral blood flow by means of the nitrous oxide technique (4) during sleep were made in approximately fifty, healthy, young, male volunteers varying in age from 17 to 36 years. In order to facilitate the induction of sleep under the conditions of the study, the subjects had remained awake for a period of approximately 20 hours, or about six hours beyond their normal bed-time, prior to the study. They are, therefore, referred to as "fatigued." Except for making the subjects as comfortable as the procedure would allow, no drugs or other special methods for inducing sleep were employed. The studies were performed in the early morning hours, most often between 4 and 6 A.M., when the tendency to fall asleep after a prolonged period of wakefulness is generally greatest (2). In most cases the subjects had been fasting for several hours; a few had eaten a light meal approximately two hours prior to the study.

In each study the subject was placed in the supine position, the needles were inserted in the internal jugular bulb and the femoral artery, needle electrodes for EEG recording were placed in the scalp, and a mask was strapped on the face. The subject was then permitted to rest in this position for about thirty minutes to permit any physical and emotional disturbances attending the introduction of the needles to subside. At this point the first or control blood flow determination was performed. The room was then darkened and quieted, and the subject, still in the same position, was given an opportunity to fall asleep. During this period the subject was usually permitted to breathe room air through a valve connected to the mask. In a few cases compressed air was fed from a tank into the mask through a reducing valve in an effort to minimize the waking effect of the gas flow associated with the nitrous oxide procedure. The state of wakefulness or sleep was followed by means of continuous EEG recordings in the adjacent room from the four to eight scalp electrodes previously inserted. These recordings were made continuously throughout the study 


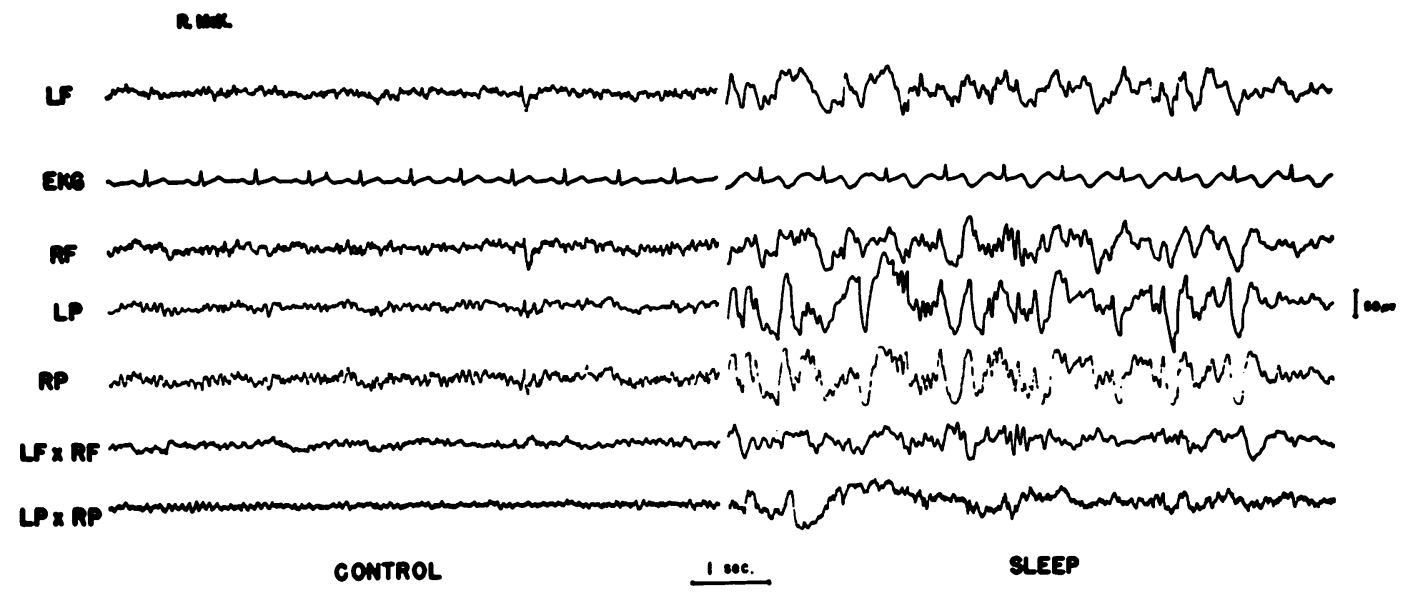

Fig. 1. Electroencephalographic Pattern During Sleep

including the periods during which cerebral blood flow measurements were being made. The mental state or level of sleep was evaluated by means of the EEG record on the basis of the classification of Gibbs and Gibbs (5) as well as by clinical observation including movements, snoring, and response to whispered commands. In no case was the subject considered asleep until after the appearance of the characteristic sleep spindles and delta waves in the EEG record (Figure 1). When, on the basis of all these criteria, the subject was considered to be in a relatively steady state of sleep, a cerebral blood flow determination was made. The above procedure was followed in all the cases in Tables IA and IB except two ( $\mathrm{P}$. O. and McK.) in which the order was reversed, sleep occurring throughout the first determination of cerebral blood flow and the control determination performed after the subjects had been awakened and kept awake for 45 and 55 minutes, respectively.

In approximately fifty attempts an uninterrupted state of sleep of sufficient depth and duration to fulfill all the criteria was achieved in only six cases. A large number of studies was discarded because independent review of the EEG record failed to confirm the presence of a steady state of sleep throughout the period of cerebral blood flow determination or revealed momentary episodes of sleep rhythms during the control period. In some of those cases in which sleep did not occur, a second cerebral blood flow determination was made under exactly the same conditions as the first to form a group of "consecutive fatigued controls" with which to study the variation between two consecutive determinations in the same individual done under identical conditions but separated in time by an interval approximating that between the control and sleep determinations.

In all the studies mean arterial blood pressure was measured with a damped mercury manometer attached to the femoral arterial needle. Blood oxygen and carbon dioxide contents were determined by the manometric method of Van Slyke and Neill (6). Total hemoglobin concentration in arterial blood was measured in the Evelyn photometer according to a modification of the method of Evelyn and Malloy (7). Measurements of blood $\mathrm{pH}$ were made anerobically at room temperature by means of a glass electrode and Cambridge potentiometer and corrected to $37^{\circ} \mathrm{C}$. by the factors of Rosenthal (8). Cerebral oxygen consumption, cerebral vascular resistance, and cerebral respiratory quotient were calculated as previously described (4). Blood carbon dioxide tension was computed by means of the nomograms of Peters and Van Slyke (9).

\section{RESULTS}

In Tables IA and IB are presented the data obtained in the six subjects on whom complete sleep studies could be made. The results obtained in the consecutive fatigued control studies in 13 subjects are presented in Tables IIA and IIB.

It is apparent that during sleep cerebral blood flow $(\mathrm{CBF})$ is increased, rising from 59 during the control state to $65 \mathrm{cc}$. per $100 \mathrm{~g}$. per min. during sleep $(p<0.01)$ while no such statistically significant change in $\mathrm{CBF}$ was found in the consecutive fatigued controls. The rise in $\mathrm{CBF}$ occurred in sleep despite a significant fall in mean arterial blood pressure (MABP) from $94 \mathrm{~mm}$. $\mathrm{Hg}$ to $90 \mathrm{~mm}$. $\mathrm{Hg}(\mathrm{p}<0.05)$. The series of consecutive studies on fatigued but awake subjects showed a significant blood pressure change in quite the opposite direction, rising from a mean of $90 \mathrm{~mm}$. $\mathrm{Hg}$ in the first to $96 \mathrm{~mm}$. $\mathrm{Hg}$ in the second determination $(p<0.01)$. This systematic change in MABP between two consecutive control determinations does not explain, however, the decrease found in sleep since the sleep series was a mixed one, sleep sometimes occurring in the first but more often 

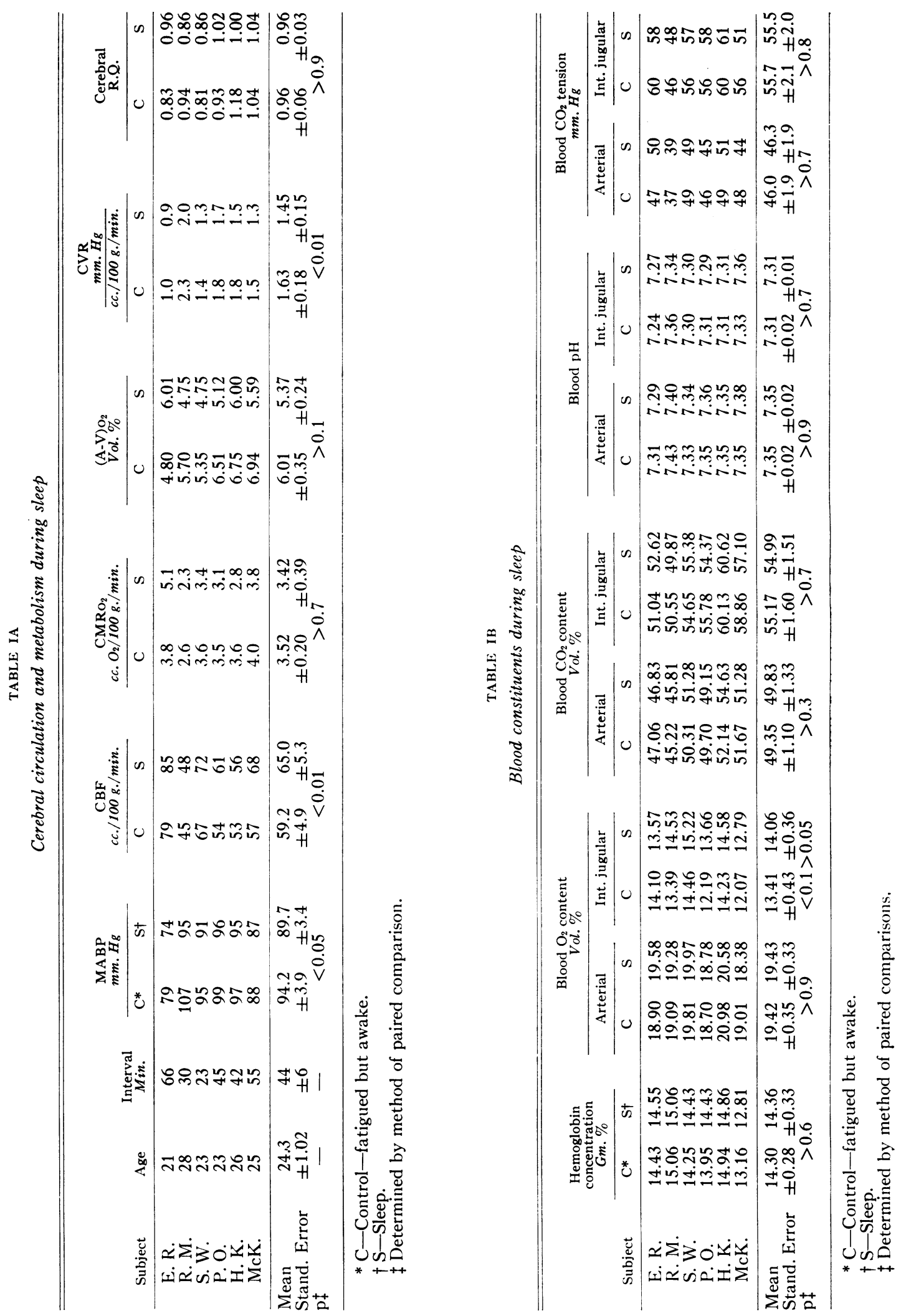
ปั.

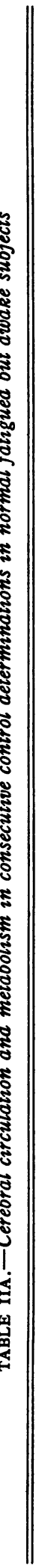
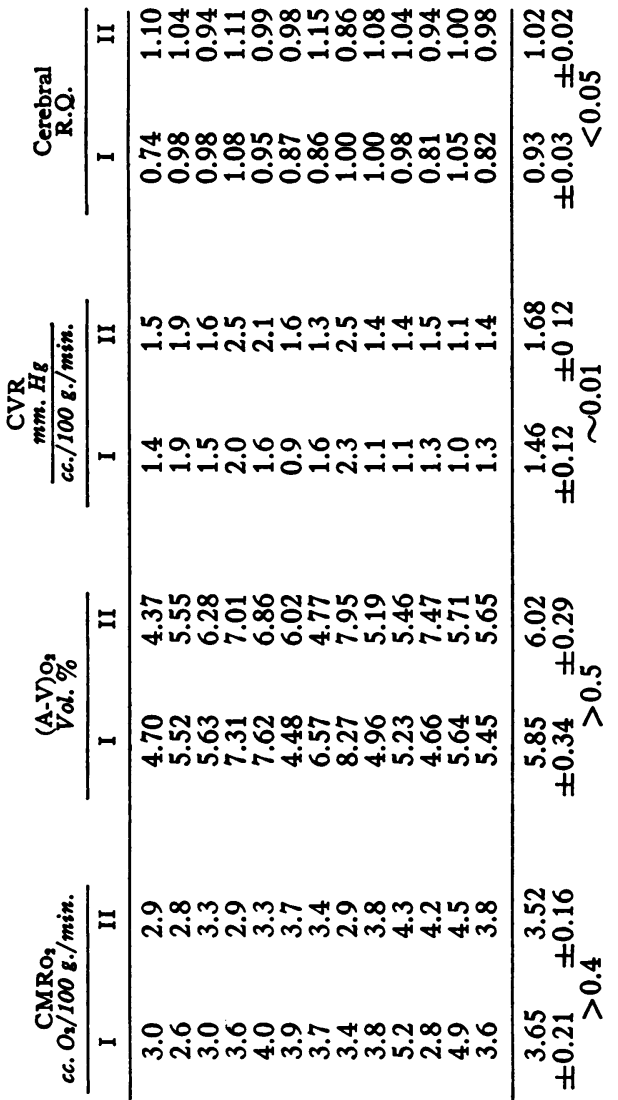

iño

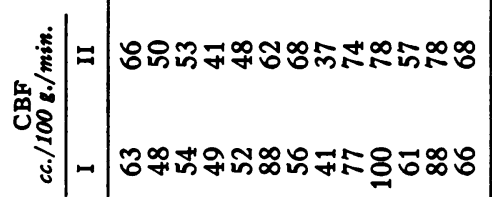

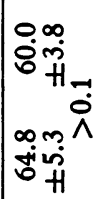

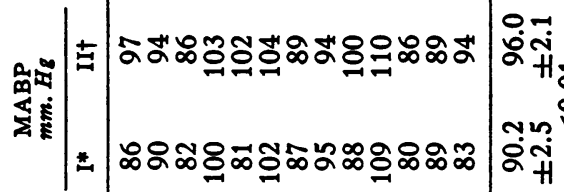

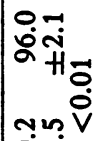

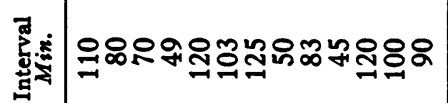

$\infty_{+1}^{\infty} \mid$

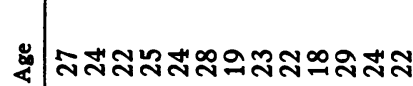

लें0

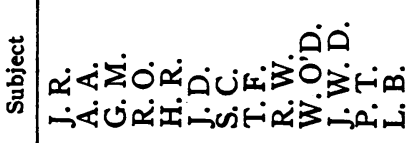

|ू.

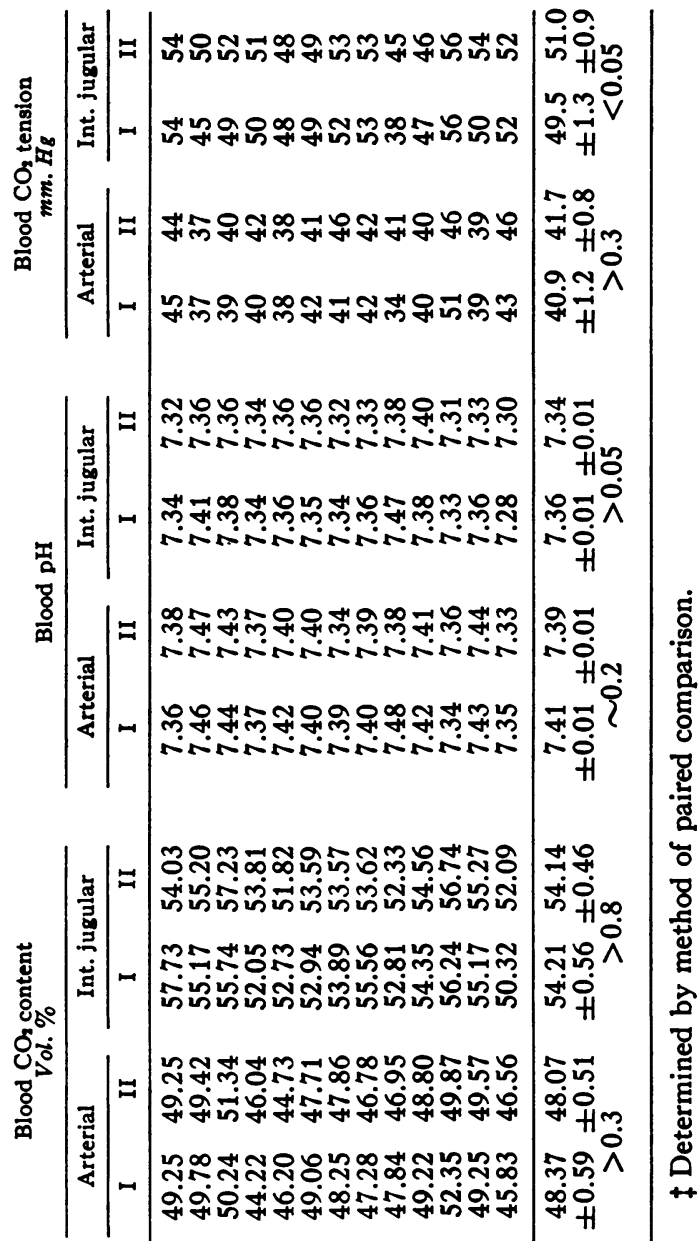

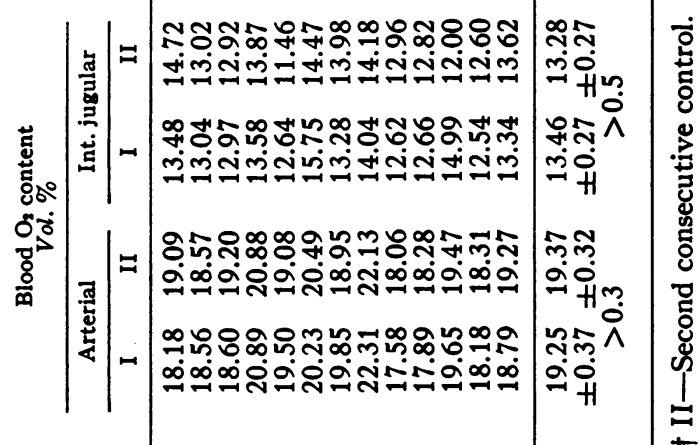

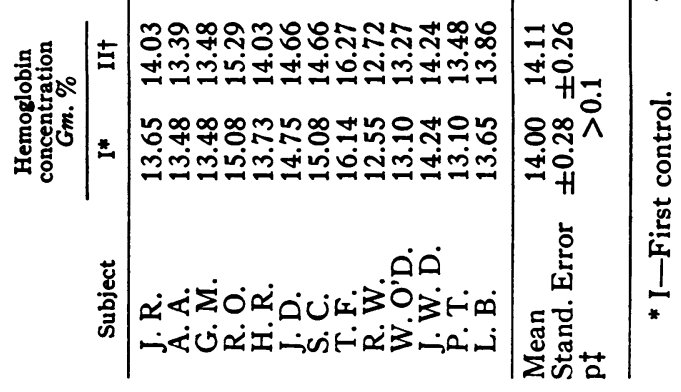




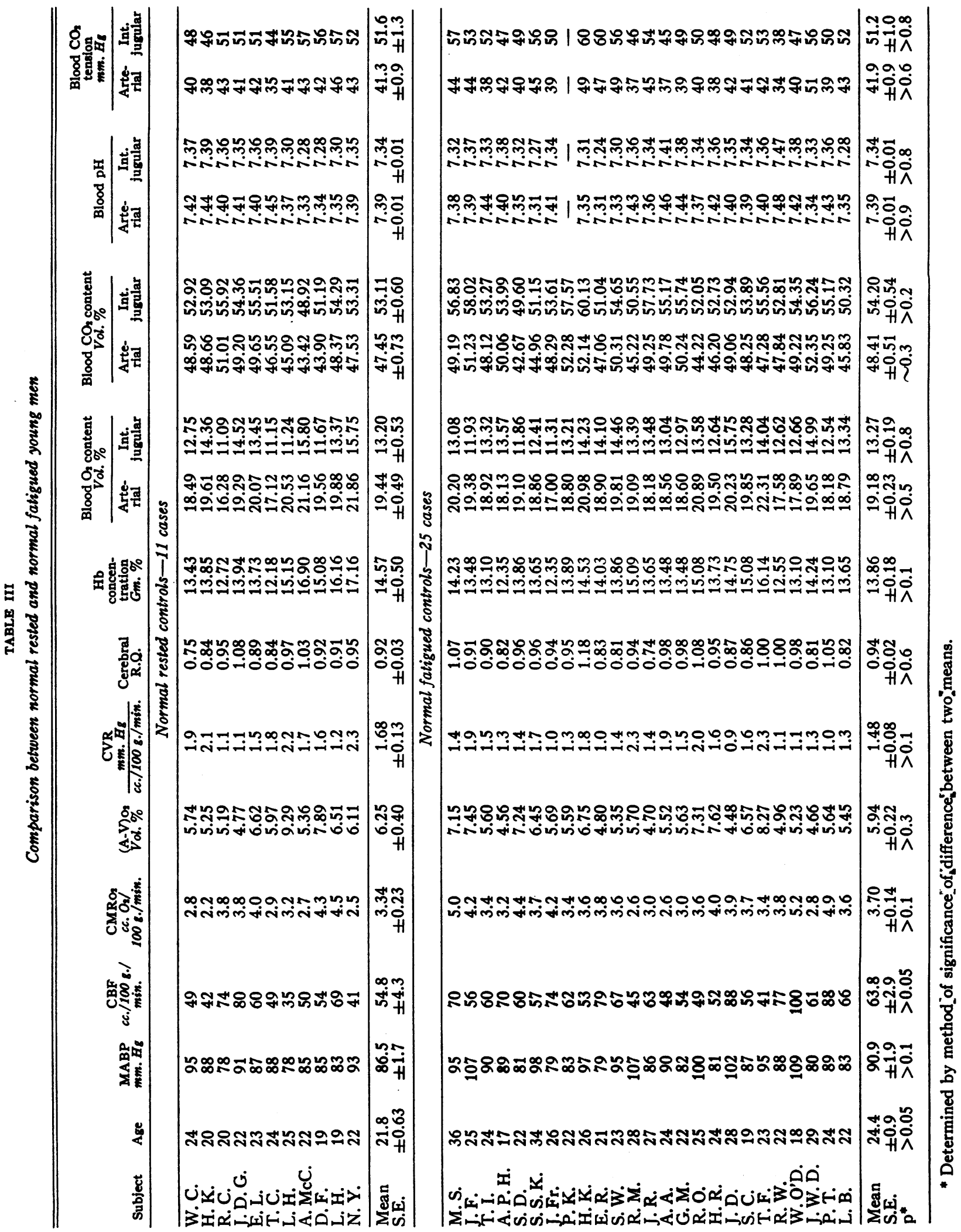


in the second of the two determinations. It seems warranted to conclude that the decreased MABP is associated with the phenomenon of sleep. The elevation of the blood pressure in the second of the consecutive controls was probably the result of the growing discomfort on the part of the subject from lying in the same position for a prolonged period.

Since $\mathrm{CBF}$ increased despite a decreased MABP, cerebral vascular resistance (CVR) must have fallen in sleep, as indicated in the change in its calculated value from 1.6 in the control determinations to $1.5 \mathrm{~mm}$. $\mathrm{Hg}$ per cc. per $100 \mathrm{~g}$. per min. during sleep $(p<0.01)$. On the other hand, CVR rose from a mean of 1.5 in the first to $1.7 \mathrm{~mm}$. Hg per cc. per $100 \mathrm{~g}$. per min. in the second of the consecutive control determinations $(\mathrm{p} \sim 0.01)$. The fall in CVR observed in sleep is probably associated with the phenomenon of sleep and, for the same reasons discussed in relation to the MABP, cannot be explained simply by the systematic difference in CVR found to exist between two consecutive control determinations.

Cerebral arterial-venous oxygen difference and cerebral oxygen consumption $\left(\mathrm{CMR}_{\mathrm{O}_{2}}\right)$ showed no significant changes in either the sleep or the consecutive control studies. Cerebral R. $Q$. did not change in sleep, but the mean value, 1.02 , in the second of the consecutive control determinations significantly exceeded the mean value, 0.93 , obtained in the first determination $(p<0.05)$, a finding for which no reasonable explanation is at hand. Arterial hemoglobin concentrations, arterial and cerebral venous oxygen and carbon dioxide contents and $\mathrm{pH}$ did not change significantly in either group. Arterial and internal jugular carbon dioxide tensions $\left(\mathrm{pCO}_{2}\right)$ were not significantly altered by sleep although it is interesting and possibly significant to note that these values were appreciably higher in the sleep group, even in their control state, than in the fatigued group which could not sleep during the studies ( $p<0.05$ and $p<0.02$, respectively). Similarly, the mean values for arterial and internal jugular blood $\mathrm{pH}$ were significantly lower in both determinations of the sleep group than in the fatigued group which failed to sleep ( $p<0.05$, respectively). In the consecutive control studies arterial $\mathrm{pCO}_{2}$ remained unchanged, but the mean value of cerebral venous $\mathrm{pCO}_{2}, 51 \mathrm{~mm}$. $\mathrm{Hg}$, in the second determination significantly exceeded the mean value, $50 \mathrm{~mm}$. $\mathrm{Hg}$, in the first determination $(p<0.05)$. This finding is probably related to the tendency for the $\mathrm{CBF}$ to decrease in the second determination.

In Table III, comparison is made between the results obtained in 25 awake but "fatigued" normal young men and those observed in 11 normal rested young men studied similarly by the same group of investigators. The values obtained in the rested subjects agree closely with those previously reported by Kety and Schmidt (4). These data are taken from the control values of various experimental procedures provided that the control determinations were made first. Thus the fatigued group includes also the first of the consecutive control determinations in Tables IIA and IIB and the control values of those sleep cases in Tables IA and IB in which the control determination was first. On the basis of this comparison, no significant differences between fatigued and rested subjects could be found although the mean value for $\mathrm{CBF}, 64$, in the fatigued group exceeded the mean value, $55 \mathrm{cc}$. per $100 \mathrm{~g}$. per min., in the rested group by an amount approaching statistical significance $(p<0.1>0.05)$.

\section{DISCUSSION}

These findings are of interest because of their pertinence to certain theories which have been advanced from time to time toward an explanation of the phenomenon of natural sleep. A number of these theories have in common the postulate that sleep is associated with and caused by a diminution in the gross nutrition or metabolism of the brain.

Quite recently, Doust and Schneider have elaborated a theory which ascribes sleep to arterial anoxemia and its resultant cerebral anoxia (10). On the basis of a downward drift in the readings of an ear oximeter, these authors concluded that arterial oxygen saturation progressively decreased during the process of falling asleep and reached levels as low as 87 per cent during deep sleep. The lack of an attempt to confirm this surprising result by more direct techniques and the absence of similar observations on non-sleeping controls leaves open the possibility, however, that it may have been one of the artifacts sometimes associated with indirect oximetry. Our findings (Table IB) 
that both the oxygen content and hemoglobin concentration of arterial blood were normal during the control period and remained unaltered during sleep make unlikely any hypothesis which attributes a causal role to arterial anoxemia.

If not the first, then certainly one of the earliest recorded theories of sleep attributed this phenomenon to an ischemia of the brain. By recording changes in intracranial volume in two subjects with cranial defects, Mosso (1) concluded that sleep was associated with a decrease in cerebral blood volume. Tarchanoff (11) supported this view by observing a blanching of the pial vessels in puppies when sleep occurred. A large number of investigators, however, were unable to corroborate the findings of Mosso or found instead evidence of cerebral vascular engorgement (1216). None of these observations yielded information on cerebral blood flow which is certainly different from and not necessarily correlated with cerebral blood volume. Only in the case of Gibbs, Gibbs, and Lennox, whose thermoelectric technique would probably have indicated if it did not measure gross changes, had observations related to cerebral blood flow in sleep been made (3). These authors were unable to demonstrate any change during sleep in the function which they studied.

The present studies show a moderate but statistically significant increase in cerebral blood flow associated with sleep. This occurred in the face of the slight but significant fall in arterial blood pressure seen in these subjects and consistently observed by numerous previous investigators (1719) and was the result, therefore, of a decreased resistance to flow somewhere in the brain. Since the intracranial pressure is usually found to rise during sleep $(14,15)$, and since the present studies demonstrate no change in hemoglobin concentration in the blood, factors of decreased external pressure or lessened viscosity appear to be ruled out, and it seems warranted to conclude that there is a relaxation in cerebrovascular tone during sleep. This supports previous observations which suggested a cerebral hyperemia during sleep (1216). The cause of this cerebrovascular relaxation remains obscure. It cannot be attributed to changes in arterial oxygen or carbon dioxide tension since these remained relatively unaltered between control and sleep, nor was it in response to an increase in cerebral metabolism which was also unaffected. The usually plausible hypothesis of a decrease in neurogenic vasoconstrictor tone is rendered less tenable by the failure to demonstrate a normal vasoconstrictor tone in the cerebral vessels of man, or at least one mediated by the known sympathetic inflow to the head (20).

Examination of the data in Table III reveals that the results in normal rested young men were almost identical with those in the original report of the method (4). When considered as a single group, the subjects who had remained awake for several hours beyond their normal bedtime and were, therefore, "fatigued," did not differ significantly in any respect from the rested young men. Within the "fatigued" group, however, arterial and cerebral venous carbon dioxide tensions were significantly higher and $\mathrm{pH}$ significantly lower in those subjects who slept than in the subjects who were unable to sleep under the conditions of the experiment (Tables IB and IIB). These differences, indicative of a mild respiratory acidosis, were apparent not only during sleep but even during the control period when the sleep subjects were awake. Comparable changes have been observed previously during sleep $(2,21)$, and Mills (22) has found elevations of alveolar carbon dioxide tension during the night or early morning irrespective of whether the subjects were awake or asleep. He attributes these changes to a normal diurnal rhythm in alveolar carbon dioxide tension which is independent of sleep. Our results indicate also that the respiratory acidosis can occur in the absence of sleep and that sleep per se causes little if any change in carbon dioxide tension and $\mathrm{pH}$ of the blood, but they raise an interesting question of whether sleep can occur in the absence of the respiratory acidosis. It was this finding which distinguished the subjects who slept from those who could not sleep under identical experimental conditions. Despite the evidence of respiratory depression, no significant anoxemia was observed in these subjects, nor was it to be expected. As Mills has also observed in his studies (22), the degree of carbon dioxide retention was insufficient to account for any appreciable fall in arterial-oxygen saturation, certainly not to the levels on which Doust and Schneider (10) based their anoxemic theory of sleep. 
Another hypothesis on the nature of sleep suggests that this state is some endogenous narcosis associated with an overall decrease in metabolic activity in the central nervous system which permits the replenishment of certain substrate stores presumably depleted by the active metabolism of the waking state. That sleep is quite different from anesthesia or coma is clearly demonstrated by the data on cerebral oxygen consumption (Table IA). Whereas coma $(23,24)$ or anesthesia (25) are associated with profound decreases in the utilization of oxygen by the brain, this function in sleep is not significantly different from its level in the waking state.

Thus the state of sleep should be added to a growing list of conditions, like schizophrenia (23) and performance of mental arithmetic (26), in which a good correlation between energy conversion and functional activity commonly found in other organ systems appears to be absent. This result is compatible with the current vogue of viewing the brain as a calculating or communicating mechanism which, in contradistinction to machines which do mechanical work, utilizes by far the greater part of its energy requirements merely in keeping its circuits alive and sensitive; the presence of a message, its functional usefulness or rationality adds only infinitesimally to the total load. Equally adequate, however, are hypotheses found more on traditional biological concepts than on electronic analogues. Thus, when the brain is considered as a great number of functional units, many of which may be reciprocally related with regard to activity, then increased activity in one group of units may result in decreased activity in others. Under such conditions, different functions could result in an altered pattern of distribution of the activity without measurable changes in the net overall oxygen consumption of the brain. Or, even more simply, is it not conceivable that the primitive functions of the brain, namely, the regulation of unconscious vegetative functions in the body, consume so much of the total cerebral oxygen requirements that they obscure the metabolic effects of the later phylogenetic functions found in conscious waking behavior, such as thought and reason?

These studies have not elicited, nor were they designed to elicit information bearing on the more subtle functional, biochemical, or electrical al- terations in sleep. They do, however, render untenable those hypotheses which attribute this important phenomenon to an anoxemia, to cerebral ischemia, to narcosis, or to a generalized depression in cerebral metabolism.

\section{SUMMARY}

1. Studies of cerebral blood flow, cerebral vascular resistance, and cerebral oxygen consumption, as well as mean arterial blood pressure, hemoglobin concentration, blood gases, and blood $\mathrm{pH}$, were made before or after and during natural sleep in six subjects, during two consecutive determinations under identical conditions in 13 subjects, during a state of fatigue in 25 subjects, and also in 11 normal rested controls.

2. The mean values obtained in the rested subjects were almost identical with the original normal values reported for the method.

3. The fatigued subjects showed no differences from the rested controls except for an elevation in cerebral blood flow which approached statistical significance.

4. During natural sleep there was a statistically significant increase in cerebral blood flow, statistically significant decreases in cerebral vascular resistance and mean arterial blood pressure, and no changes in cerebral oxygen consumption, hemoglobin concentration, and arterial oxygen content.

5. The fatigued subjects who slept were distinguished from those who were unable to sleep by significantly higher values of carbon dioxide tension and lower values of $\mathrm{pH}$ in arterial and cerebral venous blood even during the control period. These findings suggest some relationship between respiratory acidosis and the process of falling asleep.

6. The results of these studies make less tenable those hypotheses which attribute sleep to arterial anoxemia, cerebral ischemia, or to a generalized narcosis or other depression in cerebral metabolic rate.

\section{ACKNOWLEDGMENTS}

The authors wish to express their appreciation to Miss Carolyn Doernbach, Miss Hilda Klotz, and Mrs. Isabel Van den Noort for their technical assistance. 


\section{REFERENCES}

1. Mosso, A., Uber den Kreislauf des Blutes in menschlichen Gehirn. Leipzig, Viet, 1881.

2. Kleitman, N., Sleep and Wakefulness as Alternating Phases in the Cycle of Existence. Chicago, University of Chicago Press, 1939.

3. Gibbs, F. A., Gibbs, E. L., and Lennox, W. G., The cerebral blood flow during sleep in man. Brain, 1935, 58, 44.

4. Kety, S. S., and Schmidt, C. F., The nitrous oxide method for the quantitative determination of cerebral blood flow in man: theory, procedure and normal values. J. Clin. Invest., 1948, 27, 476.

5. Gibbs, F. A., and Gibbs, E. L., Atlas of Electroencephalography. Vol. I. Methodology and controls, 2nd Ed., Cambridge, Mass., Addison-Wesley Press, 1950.

6. Van Slyke, D. D., and Neill, J. M., The determination of gases in blood and other solutions by vacuum extraction and manometric measurement. J. Biol. Chem., 1924, 61, 523.

7. Evelyn, K. A., and Malloy, H. T., Microdetermination of oxyhemoglobin, methemoglobin, and sulfhemoglobin in a single sample of blood. J. Biol. Chem., 1938, 126, 655.

8. Rosenthal, T. B., The effect of temperature on $\mathrm{pH}$ of blood and plasma in vitro. J. Biol. Chem., 1948, $173,25$.

9. Peters, J. P., and Van Slyke, D. D., Quantitative Clinical Chemistry. Vol. II, Methods. Baltimore, Williams and Wilkins, 1932.

10. Doust, L. J. W., and Schneider, R. A., Studies on the physiology of awareness: anoxia and the levels of sleep. Brit. Med. J., 1952, 1, 449.

11. Tarchanoff, J., Quelques observations sur le sommeil normal. Arch. ital. de biol., 1894, 21, 318.

12. Czerny, A., Zur Kenntnis des physiologischen Schlafes. Jahrb. f. Kinderheilk., 1896, 11, 337.

13. Shepard, J. F., The Circulation and Sleep. Macmillan, New York, 1914.

14. Stevenson, L., Christensen, B. E., and Wortis, S. B., Some experiments in intracranial pressure in man during sleep and under certain other conditions. Am. J. M. Sc., 1929, 178, 663.

15. Vujic, V., Schlaf und Liquordruck. Beitrag zur Physiologie und Pathologie des Schlafes. Jahrb. f. Psychiat. u. Neurol., 1933, 49, 113.

16. Nygard, J. W., Cerebral circulation prevailing during sleep and hypnosis. Psychol. Bull., 1937, 34, 727.

17. Brooks, H., and Carroll, J. H., A clinical study of the effects of sleep and rest on blood-pressure. Arch. Int. Med., 1912, 10, 97.

18. Müller, C., and Blume, $P$., Die Messung des Blutdrucks am Schlafenden als klinische Methode. II. Acta med. Scandinav., 1921, 55, 443.

19. Landis, C., Changes in blood pressure during sleep as determined by the Erlanger method. Am. J. Physiol., 1925, 73, 551.

20. Harmel, M. H., Hafkenschiel, J. H., Austin, G. M., Crumpton, C. W., and Kety, S. S., The effect of bilateral stellate ganglion block on the cerebral circulation in normotensive and hypertensive patients. J. Clin. Invest., 1949, 28, 415.

21. Collip, J. B., Effect of sleep upon alkali reserve of the plasma. J. Biol. Chem., 1920, 41, 473.

22. Mills, J. N., Changes in alveolar carbon dioxide tension by night and during sleep. J. Physiol., 1953, $122,66$.

23. Kety, S. S., Woodford, R. B., Harmel, M. H., Freyhan, F. A., Appel, K. E., and Schmidt, C. F., Cerebral blood flow and metabolism in schizophrenia. The effects of barbiturate semi-narcosis, insulin coma, and electroshock. Am. J. Psychiat., 1948, 104, 765.

24. Kety, S. S., Polis, B. D., Nadler, C. S., and Schmidt, C. F., The blood flow and oxygen consumption of the human brain in diabetic acidosis and coma. J. Clin. Invest., 1948, 27, 500.

25. Wechsler, R. L., Dripps, R. D., and Kety, S. S., Blood flow and oxygen consumption of the human brain during anesthesia produced by thiopental. Anesthesiol., 1951, 12, 308.

26. Sokoloff, L., Mangold, R., Wechsler, R. L., Kennedy, C., and Kety, S. S., The effect of mental arithmetic on cerebral circulation and metabolism. J. Clin. Invest., 1955, 34, 1101. 